\title{
Colorimetric and Luminescent Sensors for Chloride: Hydrogen Bonding vs Deprotonation
}

2013

Vol. 15, No. 22

$5638-5641$

\author{
Robert B. P. Elmes, Peter Turner, and Katrina A. Jolliffe* \\ School of Chemistry (F11), The University of Sydney, NSW 2006, Australia \\ kate.jolliffe@sydney.edu.au
}

Received September 4, 2013

\section{ABSTRACT}

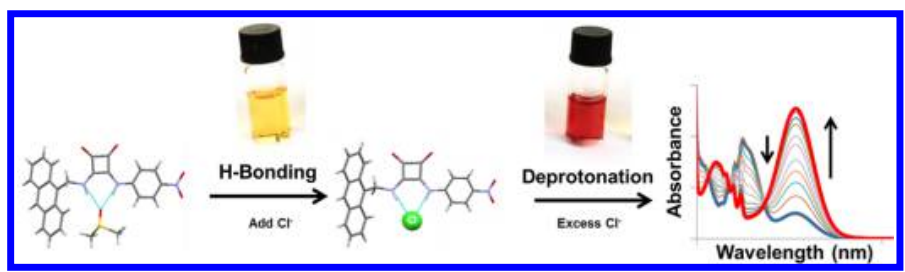

The synthesis and photophysical properties of four squaramide based fluorescent anion sensors (1-4) are described. These luminescent compounds showed selectivity for $\mathrm{Cl}^{-}$over various other anions with concomitant changes in both their UV/visible and fluorescence properties upon $\mathrm{Cl}^{-}$addition, attributed to initial $\mathrm{H}$-bonding followed by NH deprotonation in the presence of excess $\mathrm{Cl}^{-}$, signaled by a color change. The nature of the electron withdrawing aryl substituents is directly related to the H-bonding ability/acidity of the squaramide protons and can be used to tune the deprotonation behavior.

Colorimetric and luminescent sensors provide a visual method for detection of a wide range of chemical species. Substantial effort has recently been invested in the synthesis of such chemosensors for detection of anions in many diverse areas including biology, industry, and the environment. ${ }^{1-3}$ In particular, the design of charge neutral sensors capable of binding anions in competitive media, where the spectroscopic properties arising from the sensors, e.g. a color change, are modulated by addition of the external analyte has become a popular method of sensing chemical species. ${ }^{4}$ Anion recognition has been successfully achieved through the use of numerous neutral receptors 480 .

(1) Wenzel, M.; Hiscock, J. R.; Gale, P. A. Chem. Soc. Rev. 2012, 41,

(2) Cametti, M.; Rissanen, K. Chem. Soc. Rev. 2013, 42, 2016.

(3) Gale, P. A. Chem. Commun. 2011, 47,82.

(4) (a) Gunnlaugsson, T.; Glynn, M.; Tocci, G. M.; Kruger, P. E.; Pfeffer, F. M. Coord. Chem. Rev. 2006, 250, 3094. (b) Yu, G.; Zhang, Z.; Han, C.; Xue, M.; Zhou, Q.; Huang, F. Chem. Commun. 2012, 48, 2958 2960.

(5) Wang, J.; Yang, L.; Hou, C.; Cao, H. Org. Biomol. Chem. 2012, 10,6271 .

(6) Amendola, V.; Boiocchi, M.; Fabbrizzi, L.; Fusco, N. Eur. J. Org. Chem. 2011, 6434. (7) Dydio, P.; Lichosyt, D.; Jurczak, J. Chem. Soc. Rev. 2011, 40,
2971.

(8) Bullough, E. K.; Kilner, C. A.; Little, M. A.; Willans, C. E. Org. Biomol. Chem. 2012, 10, 2824.

(9) Kang, S. O.; Begum, R. A.; Bowman-James, K. Angew. Chem. Int. Ed. 2006, 45, 7882 . including imidazoles, ${ }^{5,6}$ pyrroles, ${ }^{7}$ calixarenes, ${ }^{8}$ amides, ${ }^{9}$ ureas, ${ }^{10-13}$ thioureas, ${ }^{14-19}$ amidothioureas, ${ }^{20}$ and recently thiosemicarbazides ${ }^{21}$ leading to a large body of research in the area. More recently, a characteristically different class of compounds, the squaramides, have been explored for their

(10) Sambrook, M. R.; Hiscock, J. R.; Cook, A.; Green, A. C.; Holden, I.; Vincent, J. C.; Gale, P. A. Chem. Commun. 2012, 48, 5605.

(11) Moore, S. J.; Haynes, C. J. E.; Gonzalez, J.; Sutton, J. L.; Brooks, S. J.; Light, M. E.; Herniman, J.; Langley, G. J.; Soto-Cerrato, V.; Perez-Tomas, R.; Marques, I.; Costa, P. J.; Felix, V.; Gale, P. A. Chem. Sci. 2013, 4, 103.

(12) Dos Santos, C. M. G.; Boyle, E. M.; De Solis, S.; Kruger, P. E.; Gunnlaugsson, T. Chem. Commun. 2011, 47, 12176.

(13) Amendola, V.; Fabbrizzi, L.; Mosca, L. Chem. Soc. Rev. 2010, 39,3889

(14) Veale, E. B.; Tocci, G. M.; Pfeffer, F. M.; Kruger, P. E.; Gunnlaugsson, T. Org. Biomol. Chem. 2009, 7, 3447.

(15) Lowe, A. J.; Long, B. M.; Pfeffer, F. M. J. Org. Chem. 2012, 77, 8507.

(16) Lowe, A. J.; Pfeffer, F. M.; Thordarson, P. Supramol. Chem. 2012, 24, 585.

(17) Duke, R. M.; McCabe, T.; Schmitt, W.; Gunnlaugsson, T. J. Org. Chem. 2012, 77, 3115 .

(18) Duke, R. M.; O’Brien, J. E.; McCabe, T.; Gunnlaugsson, T. $\underline{\text { Org. }}$ Biomol. Chem. 2008, 6, 4089.

(19) Dungan, V. J.; Ngo, H. T.; Young, P. G.; Jolliffe, K. A. Chem. Commun. 2013, 49, 264.

(20) (a) Young, P. G.; Jolliffe, K. A. Org. Biomol. Chem. 2012, 10, 2664. (b) Young, P. G.; Clegg, J. K.; Jolliffe, K. A. Supramol. Chem. 2011, 24, 77.

(21) Pandurangan, K.; Kitchen, J. A.; Gunnlaugsson, T. Tetrahedron Lett. 2013, 54, 2770 .

(22) Amendola, V.; Fabbrizzi, L.; Mosca, L.; Schmidtchen, F.-P. Chem.-Eur. J. 2011, 17, 5972. 
molecular recognition properties. ${ }^{22}$ Comprising a conformationally rigid cyclobutene structure in combination with a strong hydrogen bond donor ability, ${ }^{23}$ these moieties have been exploited in numerous applications ranging from medicinal chemistry to catalysis ${ }^{24}$ and more recently in the design of new anion receptors and transporters. ${ }^{25-29}$

Scheme 1. Synthesis of Anthracene-Squaramide Conjugates 1-4
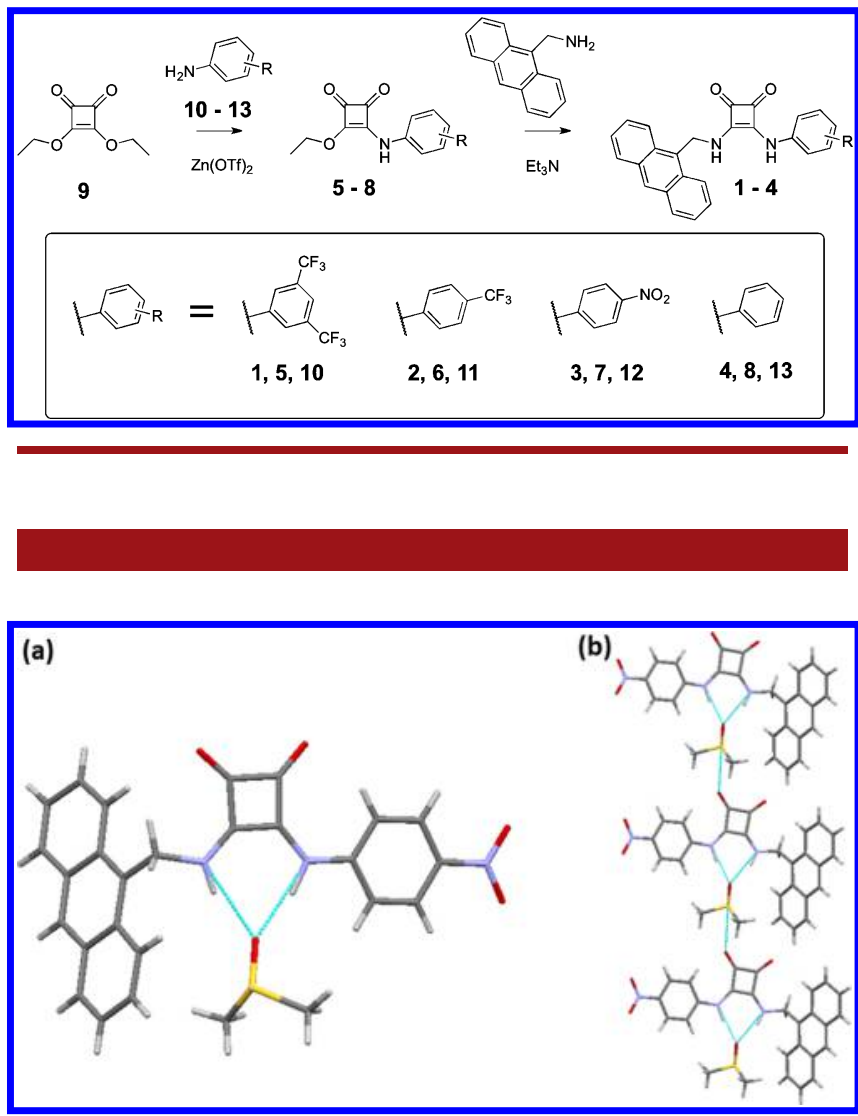

Figure 1. (a) X-ray structure of 3 bound to DMSO and (b) selfassembly network showing the $\mathrm{H}$-bond donor and acceptor ability of $\mathbf{3}$.

The intense coloration observed with sensors that make use of amide, urea, and thiourea moieties is often a result of deprotonation in the presence of basic anions and delocalization of the resulting anion throughout the receptor. Similarly, recent reports from the groups of Fabbrizzi et al. ${ }^{26}$ and Taylor et al. ${ }^{29}$ have suggested that deprotonation of the squaramide moiety by basic anions such as $\mathrm{AcO}^{-}$, $\mathrm{H}_{2} \mathrm{PO}_{4}^{-}$, and $\mathrm{F}^{-}$is even more favorable due to the negative

(23) Storer, I. R.; Aciro, C.; Jones, L. H. Chem. Soc. Rev. 2011, 40.

(24) Alemán, J.; Parra, A.; Jiang, H.; Jørgensen, K. A. Chem.-Eur.

J. 2011, 17, 6890 .

(25) Busschaert, N.; Kirby, I. L.; Young, S.; Coles, S. J.; Horton,

P. N.; Light, M. E.; Gale, P. A. Angew. Chem., Int. Ed. 2012, $51,1$.

(26) Amendola, V.; Bergamaschi, G.; Boiocchi, M.; Fabbrizzi, L.; Milani, M. Chem.-Eur. J. 2010, 16, 4368.

(27) Jin, C.; Zhang, M.; Wu, L.; Guan, Y.; Pan, Y.; Jiang, J.; Lin, C.; Wang, L. Chem. Commun. 2013, 49, 2025.

(28) Porel, M.; Ramalingam, V.; Domaradzki, M. E.; Young, V. G.;

Ramamurthy, V.; Muthyala, R. S. Chem. Commun. 2013, 49, 1633.

(29) Rostami, A.; Colin, A.; Li, X. Y.; Chudzinski, M. G.; Lough,

A. J.; Taylor, M. S. J. Org. Chem. 2010, 75, 3983. charge delocalization being extended to the entire molecular framework. Considering the unique properties of the squaramide functional group, we set out to exploit their strong anionic recognition potential by synthesizing a family of spectroscopically responsive receptors for anions. Herein, we describe the synthesis of receptors $\mathbf{1}-\mathbf{4}$ based on a squaramide recognition moiety covalently tethered to a luminescent anthracene reporter group, which has been used extensively in the field of luminescent anion recognition, including in previously reported urea and thiourea analogues of $1-4{ }^{4}$ By incorporating various electron withdrawing substituents, such as trifluoromethyl and nitro groups, on the squaramide aryl substituent we envisaged being able to 'tune' both the selectivity and sensitivity of the anion recognition.

Unsymmetrical squaramides $\mathbf{1 - 4}$ were synthesized by the reaction of 9-aminomethyl anthracene ${ }^{30}$ with the corresponding squarate monoesters $(\mathbf{5}-\mathbf{8})$ to afford $\mathbf{1 - 4}$ in $75 \%, 79 \%, 94 \%$, and $96 \%$ yield, respectively (Scheme 1). The monoesters were assembled via a room-temperature coupling of diethyl squarate (9) with the appropriate anilines $(\mathbf{1 0 - 1 3})$ in the presence of $\mathrm{Zn}(\mathrm{OTf})_{2}{ }^{29}$ (see Supporting Information (SI) for experimental details). Crystals suitable for single crystal X-ray analysis were obtained for $\mathbf{1}-\mathbf{3}$ by recrystallization from concentrated DMSO solutions allowing the evaluation of their solid-state behavior (Figure 1). Tables of H-bonds, data collection, and refinement details can be found in the SI. 1, 2, and $\mathbf{3}$ were each found to be H-bonded to a DMSO molecule in the solid state with the squaramide moiety acting as both a $\mathrm{H}$-bond donor and acceptor to a pair of DMSO molecules in the crystal lattice. Stacking interactions between the anthracene moieties were also clearly evident in the packing structure of each analogue (SI). With receptors 1-4 in hand, we next evaluated their ability to detect anions in solution by titration of 'nonbasic' anions $\mathrm{Cl}^{-}, \mathrm{Br}^{-}, \mathrm{I}^{-}$, and $\mathrm{NO}_{3}{ }^{-}$as their tetrabutylammonium salts $\left(\mathrm{TBA}^{+}\right)$, observing any changes in both their ground and excited state properties. In contrast to studies by Taylor et al., ${ }^{29}$ the presence of only a single electron withdrawing aryl group on the squaramide did not result in deprotonation in DMSO. Upon titration of these sensors with $\mathrm{Br}^{-}, \mathrm{I}^{-}$, and $\mathrm{NO}_{3}{ }^{-}$, very minor changes were seen in the absorption spectra of $\mathbf{1 - 4}$ suggesting that little interaction of these anions is occurring at the squaramide. In contrast, much more significant changes were seen upon addition of $\mathrm{Cl}^{-}$. Large modulations were observed in the absorption spectra of $\mathbf{1} \mathbf{- 3}$ but only minor changes were observed for 4 . The absorption spectrum of $\mathbf{1}$ changed significantly upon incremental additions of $\mathrm{Cl}^{-}$with a $44 \%$ increase in absorption of its band at $393 \mathrm{~nm}$ being observed and a concomitant decrease in the band at $355 \mathrm{~nm}$ resulting in an isosbestic point at $360 \mathrm{~nm}$. Similarly, 2 showed a $55 \%$ increase at $393 \mathrm{~nm}$ and a decrease of the $355 \mathrm{~nm}$ band also resulting in an isosbestic point at $360 \mathrm{~nm}$. The changes for both $\mathbf{1}$ and $\mathbf{2}$ culminated in a color change from colorless to yellow, observable to the naked eye upon addition of excess $\mathrm{Cl}^{-}$. The nitro derivative 3 displayed more dramatic

(30) Gunnlaugsson, T.; Davis, A. P.; O’Brien, J. E.; Glynn, M. Org. Biomol. Chem. 2005, 3, 48. 


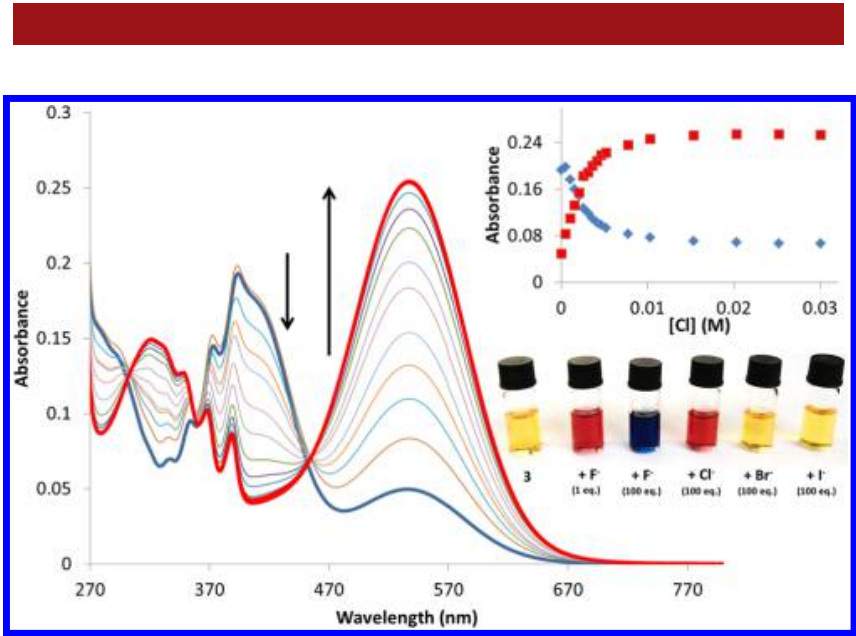

Figure 2. Changes observed in the absorption spectrum of $1(1 \times$ $\left.10^{-5} \mathrm{M}\right)$ upon addition of TBACl $(0-0.03 \mathrm{M})$ in DMSO. (Inset): Absorbance changes observed at $393 \mathrm{~nm}(\diamond)$ vs $540 \mathrm{~nm}(\boldsymbol{\square})$ and the corresponding changes seen by the naked eye with various halide anions.

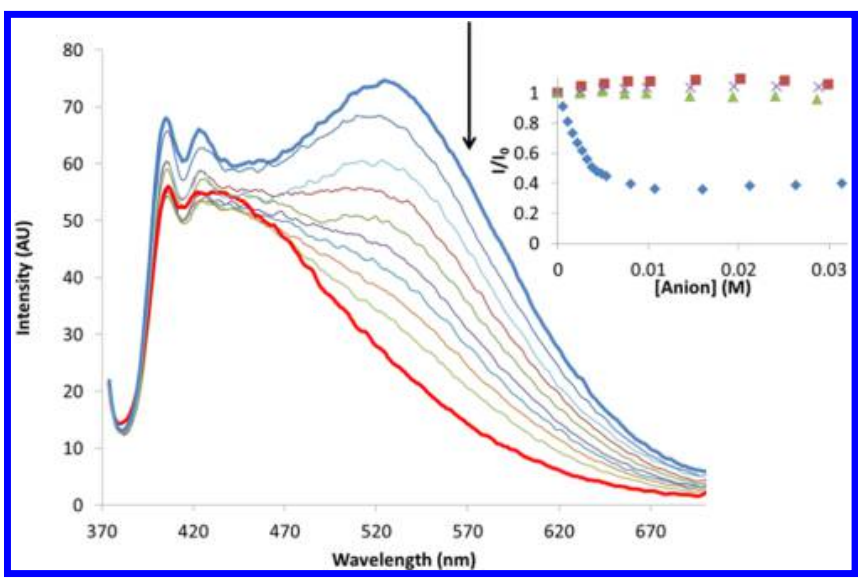

Figure 3. Changes observed in the fluorescence emission spectrum of $1\left(1 \times 10^{-5} \mathrm{M}\right)$ upon addition of TBACl $(0-0.03 \mathrm{M})$ in DMSO. (Inset): Relative emission measured at $530 \mathrm{~nm}$ in the presence of increasing concentrations of $\mathrm{Cl}^{-}(\bullet), \mathrm{Br}^{-}(\boldsymbol{\square}), \mathrm{I}^{-}(\mathbf{\Delta})$, and $\mathrm{NO}_{3}^{-}(\times)$.

changes. As shown in Figure 2, addition of $\mathrm{Cl}^{-}$resulted in the decreasing absorbance of the bands at 380 and $400 \mathrm{~nm}$ coupled to absorbance increases in the bands at 360 and $540 \mathrm{~nm}$ with the emergence of a new band at $325 \mathrm{~nm}$. Moreover, each of the bands also exhibited blue shifts of $\sim 5-10 \mathrm{~nm}$ for each of the anthracenyl transitions. These changes resulted in a color change from orange to deep pink/red. From these titrations we estimated the stability constants $(\log \beta)$ for chloride to be $\sim 2.93,2.06$, and 2.83 for squaramides $\mathbf{1}, \mathbf{2}$, and $\mathbf{3}$, respectively, which are considerably higher than those of the urea and thiourea analogues for which a $\log \beta$ value for $\mathrm{Cl}^{-}$could not be calculated under the same conditions. ${ }^{31}$

(31) Dos Santos, C. M. G.; Glynn, M.; McCabe, T.; Seixas de Melo, J. S.; Burrows, H. D.; Gunnlaugsson, T. Supramol. Chem. 2008, $20,407$.
In general, the observation of large changes in the ground state properties of neutral anion sensors is a result of a deprotonation event. $\mathrm{F}^{-}$is one of the more basic anions and is known to deprotonate ureas, thioureas, and squaramides. ${ }^{2,26}$ However, to the best of our knowledge, $\mathrm{Cl}^{-}$ anions have not previously been shown to result in deprotonation of a H-bond receptor. To determine whether the changes we observed upon addition of $\mathrm{Cl}^{-}$to receptors 1-3 were due to deprotonation or $\mathrm{H}$-bonding, a series of $\mathrm{F}^{-}$ titrations were also undertaken. Upon addition of $\mathrm{F}^{-}$to $\mathbf{1}$ and $\mathbf{2}$, a stark color change was immediately observed from colorless to yellow in a manner analogous to that described for $\mathrm{Cl}^{-}$. Such changes suggest that deprotonation is responsible for the color changes observed with excess $\mathrm{Cl}^{-}$. Sensor 3 also exhibited a color change from orange to deep pink at low concentrations of $\mathrm{F}^{-}$as was seen with $\mathrm{Cl}^{-}$, but further additions of $\mathrm{F}^{-}$resulted in a second color change from pink to blue/purple suggesting a second deprotonation event (Figure 2) as has been previously observed for bis(4nitrophenyl) substituted squaramides in the presence of excess $\mathrm{F}^{-} .{ }^{29}$ We confirmed this deprotonation behavior by titration of $\mathbf{3}$ with $\mathrm{TBAOH}$, which resulted in analogous changes (SI) where the formation of a band at $540 \mathrm{~nm}$ corresponding to the mono-deprotonated species (red) was observed initially but was followed by a decrease in the band at $540 \mathrm{~nm}$ and the concomitant formation of a new absorption band at $675 \mathrm{~nm}$ corresponding to the doubly deprotonated derivative (blue). These results indicate for the first time that, when strong electron withdrawing groups are attached to the squaramide moiety, it is possible to detect $\mathrm{Cl}^{-}$ions by a color change induced by deprotonation.

Having observed such stark colorimetric changes in the ground state properties of 1-4 we were also keen to investigate their excited state properties in the presence of each of the anions described above. Gunnlaugsson and co-workers have published a number of examples of PET sensors based on the combination of anthracene and both ureas and thioureas; ${ }^{30,31,33}$ however, to the best of our knowledge such sensors taking advantage of the squaramide moiety have not yet been reported. As such, we expected that interaction of anionic guests with the squaramide based receptors would result in significant changes to their excited state properties. Again, minor changes were observed in the emission spectra of $\mathbf{1 - 4}$ upon titration with $\mathrm{Br}^{-}, \mathrm{I}^{-}$, and $\mathrm{NO}_{3}{ }^{-}$, further confirming the minimal nature of interaction of these anions with any of the receptors. Titration with $\mathrm{Cl}^{-}$, however, led to much more significant changes as shown in Figure 3 for 1, where fluorescence quenching was observed. The observed excimer emission centered at $530 \mathrm{~nm}$ was significantly "switched off" by $66 \%$ in the presence of $\mathrm{Cl}^{-}$ions. A similar effect was observed for 2 but with a smaller emission decrease of $28 \%$ being exhibited. Although the excimer emission at $530 \mathrm{~nm}$ was less obvious in the case of $\mathbf{3}$, it too underwent an emission decrease and these changes corresponded well to those observed for 1 (SI). The emission spectrum of

(32) Nishizawa, S.; Kato, Y.; Teramae, N. J. Am. Chem. Soc. 1999, $121,9463$. 


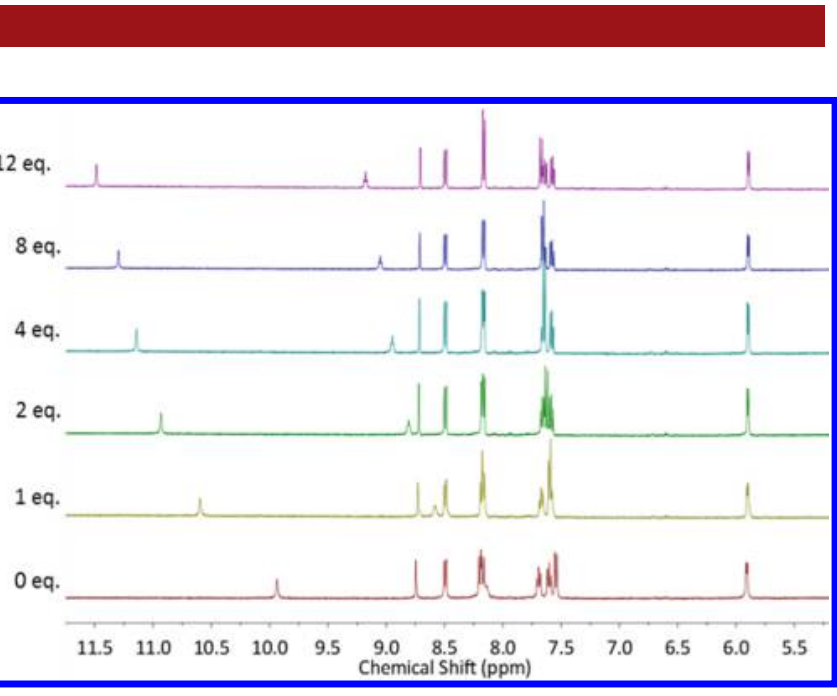

Figure 4. Stack plot of ${ }^{1} \mathrm{H}$ NMR spectra of $3\left(2.5 \times 10^{-3} \mathrm{M}\right)$ upon addition of $\mathrm{TBACl}\left(0-12\right.$ equiv) in DMSO- $d_{6}$ at $25^{\circ} \mathrm{C}$.

compound $\mathbf{4}$ did not change significantly upon addition of $\mathrm{Cl}^{-}$. Interestingly, in all cases, the monomer emission of the anthracene moiety itself remained largely unchanged, even upon addition of large concentrations of anion, and this suggests that these sensors are not PET sensors; rather their sensing ability is due to their ability to modulate excimer formation, a phenomenon described in a number of reports by Teramae et al. ${ }^{32,34}$

We performed ${ }^{1} \mathrm{H}$ NMR spectroscopic investigations in DMSO- $d_{6}$ with each of the sensors 1-4 to establish the stoichiometry of their anion complexes while gaining an understanding of the mechanism of host-guest interactions. Similarly, we sought to investigate the effect of the substitution pattern of the phenyl substituents. The data obtained from these titrations, where possible, were plotted as the cumulative changes in chemical shift $(\Delta \delta)$ against the equivalents of anion added, and the resulting plots were analyzed using Hyperquad. Figure 4 shows the changes observed in the ${ }^{1} \mathrm{H}$ NMR spectrum of $\mathbf{3}$ upon the addition of $\mathrm{Cl}^{-}$. These changes together with the solid state analysis of these compounds (see below) clearly support a classical $\mathrm{H}$-bonding interaction between the anions and the $\mathrm{NH}$ protons of the sensors at low $\mathrm{Cl}^{-}$concentrations. The binding constants $(\log \beta)$ of $\mathbf{1}-\mathbf{4}$ (determined by Hyperquad) with $\mathrm{Cl}^{-}$were calculated as $\sim 2.25,2.13$, 2.02, and 1.75 for $\mathbf{1}, \mathbf{2}, \mathbf{3}$, and $\mathbf{4}$, respectively. On all occasions a good fit to a 1:1 binding isotherm was observed; this was further supported by Job's plot analysis which confirmed a 1:1 binding stoichiometry (SI). The overall results from the $\mathrm{Cl}^{-} \mathrm{NMR}$ titrations demonstrate the same trend as observed for the ground and excited state studies described above, and highlight the effect the substituents have on the anion affinity of these sensors. Moreover, addition of a large number of equivalents ( 30 equiv)

(33) Gunnlaugsson, T.; Davis, A. P.; Glynn, M. Chem. Commun. 2001, 2556.

(34) Nishizawa, S.; Kaneda, H.; Uchida, T.; Teramae, N. J. Chem. Soc. Perkin Trans. 2 1998, 2325.

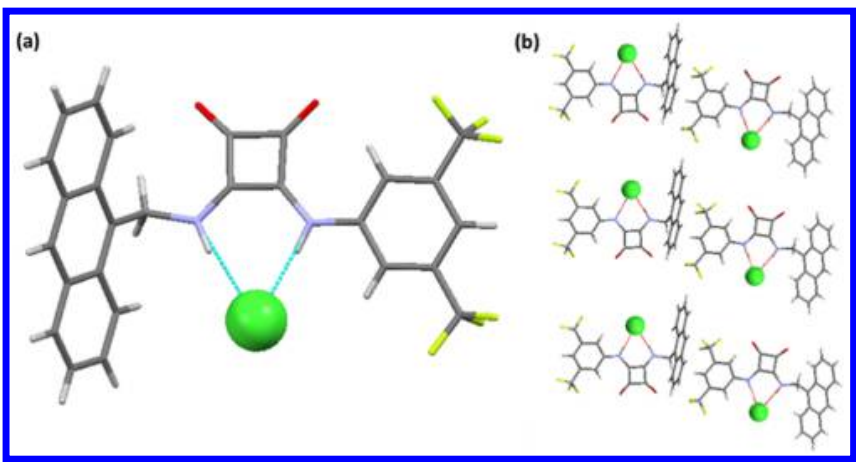

Figure 5. (a) Single crystal X-ray structure of the chloride complex of compound $\mathbf{1}$ and (b) self-assembly network formed between $\mathrm{Cl}^{-}$and $\mathbf{1}$. Counterions have been omitted for clarity.

of $\mathrm{Cl}^{-}$led to the disappearance of the $\mathrm{NH}$ signals and stark color changes of the titration solutions of $\mathbf{1}-\mathbf{3}$ but not of $\mathbf{4}$ providing further evidence of deprotonation of these sensors in the presence of $\mathrm{Cl}^{-}$at high concentrations, a phenomenon usually only reported for the more basic $\mathrm{F}^{-}, \mathrm{AcO}^{-}$, or $\mathrm{H}_{2} \mathrm{PO}_{4}{ }^{-}$anions. Similarly, mass spectrometry analysis of these solutions confirmed the presence of $[\mathrm{M}-\mathrm{H}]^{-}$ions further supporting the observations described above (SI).

Crystals of both $\mathbf{1}$ and $\mathbf{4}$ suitable for X-ray diffraction were obtained in the presence of 5 equiv of tetrabutylammonium chloride (TBACl) (Figure 5). Analysis revealed that 1 forms a 1:1 (receptor/anion) complex with $\mathrm{Cl}^{-}$at this concentration where the encapsulated anion is bound by two H-bonding interactions with both available squaramide $\mathrm{NH}$ groups. Similarly, the unfunctionalized aryl squaramide 4 also forms a 1:1 complex with chloride, where the anion is again bound by two H-bonding interactions with both available squaramide $\mathrm{NH}$ groups. Interestingly, in the case of $\mathbf{1}$, the $\mathrm{N}-\mathrm{Cl}$ distance is shortest on the 3,5-trifluoromethylphenyl side of the squaramide, again demonstrating the effect of the more electron withdrawing substituent on the $\mathrm{H}$-bond donor ability of the squaramide $\mathrm{NH}$.

In summary, we have successfully synthesized a family of receptors capable of distinguishing between halide anions by both colorimetric and luminescent modulations. We have demonstrated that the acidity of the squaramide can be effectively tuned by various aryl substituents and this provides for a novel method of selectively recognizing $\mathrm{Cl}^{-}$ anions via deprotonation of the squaramide $\mathrm{NH}$ proton. We are currently investigating these and related systems in more detail, and results will be reported in due course.

Acknowledgment. We thank the ARC (DP110100682) and USyd for financial support.

Supporting Information Available. Experimental procedures and spectral data for 1-4 as well as spectroscopic titration curves, Job plots, and crystallographic data. This material is available free of charge via the Internet at http://pubs.acs.org.

The authors declare no competing financial interest. 